Reseña de: Guillermo Lariguet, La ética frente al espejo. Ensayos sobre filosofía moral, literatura y derecho, Tirant lo Blanch, Valencia, 2020.

\title{
Graciela Vidiella*
}

La filosofía y la literatura han tenido un encuentro particularmente feliz en este libro pródigo en desafíos conceptuales y capaz de despertar el interés -o de reavivarlo- tanto por lecturas de ficción como por lecturas filosóficas del más variado espectro temático y epocal.

Lariguet, que reivindica el valor cognitivo de la metáfora, pergeña una al comienzo de la obra, la de laboratorio conceptual, metáfora que articula el modo de abordar los numerosos textos literarios con las cuestiones teóricoprácticas que presenta en cada uno de los capítulos. Un laboratorio donde la materia de los experimentos la provee la literatura y el filósofo la organiza conceptualmente a la vez que, mediante ella, refina y pone a prueba los conceptos y problemas con los que ha ido a indagarla -si se acepta esta vaga alusión a Kant. La metáfora del laboratorio se complementa con otra, la del espejo, palabra presente en el título del libro. Un espejo donde el filósofo se mira y mira al mundo no sólo como experto sino como ser humano que vive en un tiempo histórico determinado, en una sociedad determinada y se preocupa y ocupa por problemas que, si bien pueden atravesar distintos períodos, se encarnan en el presente. Porque la literatura aporta desde sus mismos orígenes, a entender de Lariguet $-\mathrm{y}$ difícilmente uno podría no acordar con ello- problemas éticos y jurídicos centrales: conflictos y dilemas morales, la cuestión de las obligaciones, la pugna entre el bien y el mal, el rol desempeñado por la fortuna en las elecciones y decisiones de vida, la libertad, la responsabilidad, la identidad personal, la intencionalidad, la racionalidad, las emociones, etc., etc. Estos $-\mathrm{y}$ algunos más- constituyen el material que

\footnotetext{
* Doctora en Filosofía por la Universidad de Buenos Aires. Se desempeñó como Profesora Adjunta Ordinaria de Ética de la Facultad de Filosofía y Letras de la Universidad de Buenos Aires, de la Facultad de Humanidades y Ciencias de la Educación de la Universidad Nacional de La Plata y como Profesora Titular Ordinaria de la Facultad de Humanidades y Ciencias de la Universidad Nacional del Litoral. Dirección electrónica: gravidiella@gmail.com
} 
compone los diez capítulos del libro. Como se advierte en esta enumeración, se entrecruzan cuestiones de filosofía práctica con problemas de filosofía de la mente, metafísica, psicología, filosofía de la acción, lo que revela que Lariguet descree $-\mathrm{y}$ esto es uno de los aciertos de la obra- de una filosofía ultraespecializada, segmentada en compartimentos estancos, más producto de una burocratización de la profesión que de una genuina curiosidad filosófica.

Ahora bien, ¿por qué la filosofía práctica necesita de este laboratorio conceptual? Porque la literatura -la buena, claro está- nos ofrece un tipo de experimentos mentales con carnadura y verosimilitud. Sin pretender en absoluto desmerecer la contribución que proporcionan los experimentos mentales a la hora de poner a prueba hipótesis -piénsese en la máquina de experiencias de Nozick, o en el aborto y el dilema del violinista, de Jarvis Thomson, por mencionar sólo dos muy famosos y recurridos-, estos suelen caracterizarse por la artificiosidad y por la posibilidad de ser maniobrados según los fines de su creador; además, debido a sus características, involucran, tanto por parte del autor como de sus receptores, habilidades exclusivamente intelectuales, como no podría ser de otra manera ya que proponen juegos especulativos. En cambio, una pieza literaria pone en movimiento capacidades afectivas y perceptivas que, a decir de Lariguet, alientan una mejor comprensión de la cuestión que se trata. Transitando el camino que inauguró en época contemporánea Ronald de Sousa y que desde hace años recorre Martha Nussbaum, el autor tiene la convicción de que las emociones pueden muchas veces proporcionarnos materiales cognitivamente útiles ayudándonos a enfocar mejor el problema al que nos enfrentamos; ellas serían las responsables de que nuestra atención se detenga en aspectos que el intelecto, librado a sí mismo, probablemente hubiera pasado por alto y que sin embargo son importantes a fin de caracterizar adecuadamente el asunto que nos ocupa. Esta tesis se "encarna" sobre todo en una de las elecciones literarias contenidas en el capítulo cuarto, la novela La ley del menor del escritor inglés Ian McEwan, empleada aquí para poner a prueba la idea normativa de razonabilidad a la que, entre otras, apela el Derecho para justificar decisiones judiciales conflictivas. Ante un caso como el que le toca resolver a la jueza de familia Fiona May es muy probable que nuestras intuiciones meditadas consideren que lo razonable es proteger los intereses del menor fallando a favor del hospital; ¿cómo se podría razonablemente dudar de que esta es la mejor opción? (La jueza debe dictaminar si hace lugar al requerimiento de un hospital para realizar una 
transfusión de sangre a un menor próximo a cumplir la mayoría de edad, testigo de Jehová, quien, apoyado por sus padres, se niega a recibirla, a sabiendas de que su negativa le provocará una muerte segura y una agonía dolorosa). Sin embargo, la novela nos permite descubrir la compleja trama de emociones, sentimientos, relaciones personales y consecuencias que pueden presentarse en un conflicto de este tipo, aquí personificados en sus dos protagonistas, la propia jueza, funcionaria experimentada y reconocida por sus fallos ejemplares, y el joven decidido a morir por sus convicciones religiosas. La decisión de la funcionaria, que se ha pronunciado por preservar la vida del menor, lleva a un final trágico, y Fiona May se cuestiona sobre la razonabilidad de su decisión y se siente culpable por el desenlace. No es que se arrepienta, que piense que debería haber dictaminado de otro modo para evitar una tragedia que de ningún modo podría haberse evitado, pero, aun así, aun sabiendo que si hubiera obrado de otro modo la pregunta seguiría atormentándola, no puede de dejar de preguntarse: ¿Actué razonablemente? $\mathrm{Y}$ nosotros, lectores comunes, o filósofos, o juristas, leyendo esta novela hemos podido ensanchar nuestra imaginación y percepción moral, clarificado conceptos, comprendido mejor y reflexionado de un modo más profundo, en suma, hemos realizado un aprendizaje moral.

Ahora bien, ese aprendizaje, ¿es sólo epistémico o nos hace mejores moralmente? En verdad se trata de una cuestión muy discutida. Nussbaum es una optimista defensora de la segunda alternativa (también lo es, no es ocioso recordarlo, el iconoclasta Richard Rorty), sosteniendo que la lectura de ciertas novelas -en particular las realistas del siglo XIX- contribuye a desarrollar aptitudes morales que ayudan a convertirnos en mejores ciudadanos, comprometidos con la cosa pública. Una buena novela realista puede despertar nuestra imaginación dado que la narrativa convoca la capacidad de figurarse en qué consiste la vida de personas que podríamos ser nosotros mismos o algún ser cercano; también nos invita a ponernos en el lugar de prójimos muy diversos y adquirir sus experiencias, activando nuestras emociones y con ellas nuestra imaginación. Esta visión ha sido fuertemente cuestionada, por ejemplo, por Richard Posner e, incluso, por Alan Goldman -que comparte varias de las tesis de la filósofa- quienes, sin negar la influencia que pueda tener la literatura en nuestra "educación sentimental", de ninguna manera garantiza que nos eleve moralmente, no asegura que eduque nuestras emociones para que logremos, parafraseando a Aristóteles, sentir lo que es debido, del modo debido y en el 
momento debido; además, la literatura -incluso las grandes novelas realistas que le interesan a Nussbaum- están sembradas de personajes excesivos, amorales o francamente malvados que pueden reforzar en cierto tipo de lector disposiciones indeseables y hasta psicopáticas. Lariguet toma, al respecto, una posición de consciente cautela, comenzando por advertir, aristotélicamente, que para que la lectura de ficciones pueda incidir positivamente en nuestras cualidades morales es necesario, por parte del lector, poseer disposiciones adecuadas a fin de empatizar, por ejemplo, con el personaje de Winston y no con el de O'Brien de 1984 de George Orwell, o no dejarse seducir por las perversiones de Ricardo III o lady Macbeth. Por otra parte, la buena literatura, como la vida, está llena de personajes complejos, de situaciones matizadas y ambiguas desde el punto de vista moral. De modo que la pregunta con la que Lariguet culmina el tratamiento de este asunto es: ¿qué significa ser mejor persona? Responde afirmando -y por ello reclama un lector activo, reflexivo e imaginativo- que se trata de una búsqueda y de un esfuerzo por elevarse sobre el umbral de lo que somos. Duda, entonces, de que la literatura sea una condición necesaria y -mucho menos- una condición suficiente de nuestra educación moral, sino, en todo caso, una condición contribuyente, esto es, valiosa, sí, pero no insustituible ni garante de aquella. Lo que este arte puede ofrecernos, eso sí, es un camino hacia el autoconocimiento, que es uno de los aspectos de nuestra educación sentimental. En este punto correspondería, quizá, desambiguar el concepto: la educación sentimental no es lo mismo que la moral, aunque ambas se relacionan con el aprendizaje emocional. Leyendo una ficción es posible verse reflejado en caracteres y situaciones que pueden ayudar a comprenderse mejor a uno mismo en un sentido no meramente epistémico sino, digamos, existencial. Quizá no sea excesivo afirmar que las obras que han marcado hitos en nuestra historia personal, esas a las que, de un modo u otro, solemos volver a lo largo de los años, como cuenta Lariguet que le ocurrió con La guerray la $p a z$, nos hayan producido una conmoción profunda porque nos revelaron cosas de nosotros mismos que desconocíamos o que apenas atisbábamos, de modo que luego de leerlas ya no somos los mismos (aunque, en un punto, seguimos siéndolo, de otra manera ¿por qué continúan interpelándonos?) Sin embargo, esto no significa que nos hayan ayudado a convertirnos en mejores personas desde el punto de vista moral. Al inicio del libro se reproduce una cita de John Coetzee que transcribo en parte: "Lo que escribimos puede ponernos en peligro, o eso creo yo. Porque si lo que escribimos tiene el poder de hacernos mejores, 
seguramente tiene el poder de hacernos peores". Creo que no sería errado reemplazar "escribimos" por "leemos".

Como es fácil advertir, lo anterior bordea el tema de la identidad personal, que es abordado en el capítulo séptimo a través de una novela del inquietante escritor Haruki Murakami: El fin del mundo y un despiadado país de las maravillas. El protagonista tiene su identidad escindida en dos realidades paralelas que, en determinado momento comienzan a cruzarse. Lariguet rescata de la obra problemas filosóficos propios de la filosofía de la mente, como el de la relación mente-cuerpo, los circuitos de conciencia y la identidad, que testea con distintas posiciones filosóficas, como las de Locke y Parfit, aunque también realiza consideraciones referidas a la vida buena.

Murakami es también el escritor elegido en el capítulo sexto para indagar sobre el tema del bien y el mal a través de varias de sus obras. Lo que interesa a Lariguet en esta ocasión es poner el acento en las situaciones extraordinarias que imagina el escritor japonés -y que también encuentra presentes en El señor de los anillos y hasta en los superhéroes de los comics, sin olvidar el anillo de Giges de la República de Platón- para desafiar las respuestas filosóficas a la pregunta ¿qué significa ser moral, actuar con virtud, cumplir con nuestras obligaciones? Pero las situaciones extraordinarias, esas que escapan a nuestro control, pueden llevarnos a caer en el mal aunque busquemos el bien -y, podría agregarse, a veces se persigue el mal, pero se provoca el bien, como lo mostró magistralmente Sartre en la obra de teatro El diablo y Dios. Quizá, plantea Lariguet, estos desafíos literarios nos adviertan del fracaso de las teorías éticas para establecer criterios que permitan diferenciar entre el bien y el mal; en la moral hay una indeterminación que no puede eliminarse.

Es evidente que el autor se siente muy a gusto con la narrativa fantástica y de ciencia ficción. En el capítulo quinto utiliza dos relatos de Isaac Asimov para preguntarse si cierta clase de robots podrían tener derechos morales. Lo que a priori podría parecer una interrogación desatinada, a medida que se avanza en el análisis de las ficciones, se van generando en el lector incertidumbre y cierto desasosiego dado que ¿cuán lejos estamos los humanos de convivir con robots del tipo de George Diez creado por Asimov, que no sólo razona teóricamente, sino que posee razonamiento práctico, que debe decidir entre situaciones conflictivas? En una palabra, un robot demasiado bumano.

La temática de los conflictos trágicos es una preocupación central en la obra del autor. En varios trabajos anteriores ha indagado sobre el tema 
sosteniendo que aquellos plantean un límite a la racionalidad moral y jurídica. En el libro que estamos comentando el conflicto trágico está presente en varios capítulos. Ya lo hemos tocado en relación con la novela de Mc Ewan, pero aparece también en los capítulos segundo, tercero y décimo. Interesa hacer una breve referencia al capítulo segundo, en el que se ponen en diálogo dos Antígonas, la de Sófocles y Antígona Furiosa, que la dramaturga argentina Griselda Gambaro estrenó en 1986, apenas recuperada la democracia, cuando el tema del terrorismo de estado y de los desaparecidos ocupaban un lugar de privilegio en la agenda política. Dos son las tesis principales que propone Lariguet; en primer lugar, que el género trágico contiene, entre otros, asuntos que hacen a la reflexión política; en segundo lugar, que, pese al pronóstico de un experto de la talla de George Steiner, la tragedia no ha muerto, dado que el conflicto trágico no ha muerto. El conflicto irresoluble entre physis y nomos de la Antígona clásica sigue presente en la actualidad argentina, tal como lo han demostrado los fracasos de la democracia en su tentativa por aplacarlo a través de las leyes de obediencia debida y de los indultos dictados por el presidente Menem, que no han logrado apaciguar los conflictos de valores, esos dioses en perpetua lucha que invocó Weber; las democracias deberán aprender (¿será posible?) a lidiar con ellos.

Completan el libro un capítulo -el octavo- dedicado a indagar las problemáticas relaciones entre religión y Derecho, para lo que se utiliza como material de análisis la trilogía literaria de Philip Pullman, y el capítulo noveno, donde se incluye un comentario de un libro de la filósofa española María Teresa López de la Vieja en el que se considera el giro narrativo producido en la bioética en estos últimos años.

En suma, una obra sugerente, rica en ideas y en estrategias argumentativas. Una invitación gozosa a la filosofía y a la literatura.

Recibida: 03/2021. Aceptada: 03/2021 